\title{
Enhancing resilience within and between critical infrastructure systems
}

\author{
Nancy Kete ${ }^{1} \cdot$ Giuliano Punzo ${ }^{2} \cdot$ Igor Linkov $^{3}$
}

Published online: 14 September 2018

(c) This is a U.S. Government work and not under copyright protection in the US; foreign copyright protection may apply 2018

This special issue of Environment Systems and Decisions is based on a new initiative called the Resilience Shift, a partnership between the Lloyds Register Foundation and Ove Arup \& Partners International set up to advance resilience in critical infrastructure. Resilience Shift was launched in 2016 in recognition that, although the safety and well-being of billions of people depends on infrastructure systems, at present we do not design, deliver, and operate for resilience. What design, deliver, and operate for resilience would mean in practice is the subject of the articles in this issue. For more information about Resilience Shift, please see http:// resilienceshift.org/.

Resilience Shift kicked off its work with an agenda setting exercise, calling for research proposals to map the pathways from where design and engineering practice for resilience is today to where it should be. The call asked study teams to concentrate on professional practice in the critical infrastructure sectors of water (and food), transportation, healthcare, communications, and energy, including cross-sectorial interdependencies. The research was to be relevant to practitioners including local governments, national and international NGOs, system operators, asset owners, utilities, investors, and other stakeholders.

Resilience Shift asked researchers to address the following themes which, collectively, seem to comprise a minimum set of outcomes consistent with seeing a shift towards adoption of resilience concepts in practice.

\footnotetext{
Nancy Kete

nancy.kete@arup.com

Igor Linkov

Igor.Linkov@usace.army.mil

Resilience Shift, London, UK

2 The University of Sheffield, Sheffield, UK

3 US Army Engineer Research and Development Center, Concord, MA 01742, USA
}

- Common understanding of sectors as global systems and the effect that decisions within these sectors have on the resilience of society.

- The adoption of dynamic, performance-based (resiliencebased) design approaches in broad practice.

- The adoption or use of tools to value resilience and to make sure that resilience value is realized across the project life cycle by project owners, developers, financiers, and insurers. To this we should add regulators.

- The use of integrated systems approach as context for critical infrastructure systems.

- Integration of systems thinking and resilience concepts into the education and understanding of those responsible for planning, designing, delivering, regulating, and operating critical infrastructure.

- Adoption of transformative technologies that facilitate (rather than compromise) critical system functionality.

This special issue provides a summary of several of the most important papers Resilience Shift received, that have been updated to reflect changes or advances since Resilience Shift agenda setting papers were concluded a year ago. The original set of white papers are available on the Resilience Shift website: http://resilienceshift.org/publications/.

The paper by Hickford et al. (2018) reviewed the state of the art in understanding interdependencies of critical infrastructure systems. The article identifies a significant gap between theory and current practice and confirms significant opportunity for better practical understanding of how to apply resilience theory in the design and engineering of energy, water, and transport sectors-systems with significant interdependences. The complexity of these fundamental systems results in the potential for small failures to cascade into large events of catastrophic proportions. The authors reviewed modeling approaches to describe and predict cascading events and found that the considerable volume of theoretical work has yet to be tested or applied widely in practice. And, while the US, UK, and Canada were found to 
have research programs and national strategies aiming to put resilience engineering and related disciplines at the center of infrastructure planning and management, the review found little evidence of similar work in developing countries. They recommended that further work could helpfully aim at taking advantage of infrastructure commissions and similar institutional openings to assist in translating resilience theory and science into practice.

Field and Look (2018) make both a business case and a public interest case for applying resilience concepts in planning, design, and funding critical infrastructure, noting how unacceptable it is "... to invest our finite resources in large infrastructure projects that we know will not deliver the long-term benefits needed. The money could be much more effectively invested where there is a definite future need. Cost sunk into infrastructure without a long-term business case can only serve to hinder our future competitiveness." Their paper frames resilience as capacity that adds value (even if it does increase costs) by enhancing the capacity of infrastructure systems to more successfully cope with shocks and stresses and other long-term challenges. Prioritizing resilience in infrastructure decisions means shifting away from a reactive, response-driven strategy (to shock and stress factors) towards a proactive, preventative strategy that considers whole systems and interdependencies. They explore how applying resilience thinking, via foresight modelling, value chain analysis, and applications of other systems science approaches, could help decision makers anticipate future changes and exploit future opportunities and thus result in more sustained economic competitiveness.

In their paper, "Engineering Meets Institutions," Naderpajouh et al. (2018) turn our attention to the complexity of managing for resilience, given that resilience is a property of communities, not of structures, quoting Timmerman, from a 1981 monograph. The paper reminds us that although engineering is the principal domain associated with critical infrastructure, managing critical infrastructure (CI) successfully for resilience requires an interdisciplinary approach. They provide case studies of three situations that vary significantly in the extent to which institutional factors-both social and organizational-were incorporated in decisions on managing for resilience, and discuss apparent consequences. The cases illustrate the need not to just focus on development of engineering tools, but to account for how the collective process of enhancing resilience should be organized and managed. The authors recommend institutional theory as a necessary lens through which to explore the implications of managing resilience.

Pearson et al. (2018) approach the understanding of resilience not from the perspective of a particular infrastructure system but with a focus on one increasingly common hazard: floods. The paper systematically explores three of the themes Resilience Shift suggested: integrated systems approach to projects; dynamic, performance-based design; and embedding systems thinking and resilience concepts in engineering education. This three-fold focus was chosen because the authors believe these themes are intrinsically linked and are key to delivering flood resilience.

The systems perspective to understanding and managing resilience of $\mathrm{CI}$ is imperative because $\mathrm{CI}$ systems are networked systems that produce the essential goods and services upon which society depends. And these systems have networks of dependencies within them and interdependencies between them. This describes the complexity of reality, and recent examples provided by the authors show that conventional engineering and risk assessment approaches simplify reality too much to satisfactorily address flood challenges.

Developing and using the right design approaches for flood resilience starts with understanding the performance objectives and indicators present in extant guidance documents, and the authors provide a review of this for UK, EU, and North America, with special attention to ISO 31000. The tension between risk management and resilience building and "how different understandings of this relationship impact upon the policy and practice of resilience and its adoption by CI providers emerges as critical." That brings us to a perspective, from EU-RESILENS, that in practice we need "An extension of risk management: This transitionary perspective recognizes the importance of risk management to CI operation, but proposes that these practices need to be extended to encompass resilience practice that integrates social and organizational factors, as well as building capacity to change."

Staddon et al. (2018) hone in on the contributions green infrastructure can make to urban resilience and the barriers to it being widely adopted as an alternative or complement to conventional gray infrastructure. Reminding readers that resilience is not just about the structures-gray, green, graygreen - that are intentionally designed or engineered, but also how these are conceived, (co)created, and integrated within complex socio-ecological technical systems. Resilience thus emerges out of 'why' things are done (to resolve an issue), 'how' things are done (can an intervention resolve multiple issues simultaneously?), and 'who' they are done with (direct and indirect beneficiaries or stakeholders) as well as 'what' things are done (the intervention itself). The paper goes on to review some key resilience engineering perspectives, summarize many green infrastructure tools and then looks into five important challenges to effective green infrastructure implementation. Intrinsic in the assessment and recommendations is the view of resilience as a social phenomenon as well as a physical one, and the necessity to adopt socially inclusive approaches to design and operation of hybrid socio-technical systems. 
The articles in this issue collectively help make resilience more practical, tangible, and relevant to researchers and practitioners alike. They gamely contribute to a nascent understanding of what "resilience engineering" is, even though much controversy remains over definitions of resilience, more generally. As the paper by Pearson et al. (2018) reminds us, although engineering is not the only domain that contributes to the resilience or lack thereof of critical infrastructure, society does call on and rely on engineering. Engineering is placed at the heart of creating and managing resilience. And as the review by Hickford et al. (2018) confirms that unlike most engineering sub-disciplines, which were driven by practical needs and developed over time through learning by doing, resilience engineering has mainly been driven by theory. In fact, by multiple theories. Resolution of definitions and widespread adoption of approaches, tools, and standards to consolidate resilience engineering's best practices awaits input from practical application.

\section{References}

Field C, Look R (2018) A value-based approach to infrastructure resilience. Environ Syst Decis. https://doi.org/10.1007/s1066 9-018-9701-x

Hickford AJ, Blainey SP, Hortelano AO, Pant R (2018) Resilience engineering: theory and practice in interdependent infrastructure systems. Environ Syst Decis. https://doi.org/10.1007/s1066 9-018-9707-4

Naderpajouh N, Yu DJ, Aldrich DP, Linkov I, Matinheikki J (2018) Engineering meets institutions: an interdisciplinary approach to management of resilience. Environ Syst Decis. https://doi. org/10.1007/s10669-018-9704-7

Pearson J, Punzo G, Mayfield M, Brighty G, Parsons A, Collins P, Jeavons S, Tagg A (2018) Flood resilience: consolidating knowledge between and within critical infrastructure sectors. Environ Syst Decis. https://doi.org/10.1007/s10669-018-9705-6

Staddon C, Ward S, Vito LD, Zuniga-Teran A, Gerlak AK, Schoeman Y, Hart A, Booth G (2018) Contributions of green infrastructure to enhancing urban resilience. Environ Syst Decis. https://doi. org/10.1007/s10669-018-9702-9 